\title{
Desenvolvimento vegetativo de orquídeas submetidas a diferentes formulações de macronutrientes e freqüências de adubação durante a fase de aclimatização
}

\author{
Vegetative development of orchids submitted to different \\ macronutrient formulations and fertilization frequencies during the \\ acclimatization phase
}

\author{
Alessandro Borini Lone ${ }^{1 *}$; Lúcia Sadayo Assari Takahashi²; \\ Ricardo Tadeu de Faria ${ }^{3}$; Adriane Marinho de Assis ${ }^{4}$; Lílian Keiko Unemoto ${ }^{5}$
}

\section{Resumo}

\begin{abstract}
A concentração de macronutrientes, a dose e a freqüência da aplicação da adubação afetam de maneira significativa o desenvolvimento vegetativo das plantas. O objetivo deste trabalho foi avaliar o desenvolvimento vegetativo de plantas de Cattleya intermedia $x$ Laelia purpurata, na fase de aclimatização, fertirrigadas com diferentes formulações de N-P-K e com diferentes freqüências de adubação. As formulações de N-P-K (nitrogênio, fósforo e potássio) aplicadas às plantas, juntamente com a água de irrigação, foram 10:10:10 e 6:6:8, a cada sete e quinze dias, na concentração de 2 g.L $\mathrm{L}^{-1}$, durante o período de 10 meses, mantendo-se um grupo controle, que não recebeu adubação. Após esse período foram avaliados os seguintes parâmetros: comprimento da parte aérea; comprimento da maior raiz; número de pseudobulbos; número de raízes; massa fresca total; $\mathrm{pH}$ e condutividade elétrica do substrato $\left(\mu \mathrm{S} . \mathrm{cm}^{-1}\right)$.Considerando todos os parâmetros avaliados, a fertirrigação com N-P-K 10:10:10 em intervalo de tempo de 15 dias, na concentração de 2 g.L.-1, proporcionou melhor desenvolvimento vegetativo do híbrido intergenérico Cattleya intermedia $x$ Laelia purpurata durante a fase de aclimatização.
\end{abstract}

Palavras-chave: Nutrição, Orchidaceae, produção de mudas, propagação in vitro

\begin{abstract}
The macronutrient concentration, the dose and the fertilizing application frequency affect the vegetative development of the plants in a significant way. The aim of this work was to evaluate the vegetative development of plants of Cattleya intermedia $x$ Laelia purpurata in the acclimatization phase, fertirrigated with different formulations of N-P-K and with different fertilizing frequencies. The formulations of N-P-K (nitrogen, phosphorus and potassium), applied to the plants with the irrigation water, were 10:10:10 and 6:6:8, to each seven or fifteen days, in the concentration of $2 \mathrm{~g} . \mathrm{L}^{-1}$, during 10
\end{abstract}

${ }^{1}$ Biólogo, Aluno do Programa de Pós-Graduação em Fitotecnia do Departamento de Agronomia da Universidade Estadual de Londrina/UEL, Londrina, Pr. Bolsista CNPq. E-mail: alone_bio@yahoo.com.br

2 Engenheira Agrônoma, Professora, Dra. do Departamento de Agronomia da Universidade Estadual de Londrina, UEL, Londrina, Pr. E-mail: sadayo@uel.br

3 Engenheiro Agrônomo, Professor, Dr. do Departamento de Agronomia da Universidade Estadual de Londrina, UEL, Londrina, Pr. E-mail: faria@uel.br

4 Engenheira Agrônoma, Doutora em Fitotecnia pela Universidade Estadual de Londrina, UEL, Londrina, Pr. E-mail: agroadri@, ig.com.br

5 Bióloga, Doutora em Fitotecnia pela Universidade Estadual de Londrina, UEL, Londrina, Pr. E-mail: lilianunemoto@yahoo. com.br

* Autor para correspondência 
months, mantaining a control group of plants that did not receive the fertilizers. After that period, the following parameters were appraised: length of the aerial part; length of the largest root; pseudobulbs number; number of roots; total fresh mass; $\mathrm{pH}$, and electric conductivity $\left(\mu \mathrm{S} . \mathrm{cm}^{-1}\right)$ of the substratum. Considering all parameters, the fertirrigation with N-P-K 10:10:10 in the interval time of 15 days, in the concentration of $2 \mathrm{~g} . \mathrm{L}^{-1}$, provided the best vegetative development of the intergeneric hybrid Cattleya intermedia $x$ Laelia purpurata during the acclimatization phase.

Key words: Nutrition, Orchidaceae, seedlings production, in vitro propagation

A família Orchidaceae abrange cerca de 25 mil espécies, distribuídas em mais de 600 gêneros distintos, sendo uma das famílias mais numerosas entre as fanerógamas. A grande maioria encontra-se em regiões tropicais, havendo também representantes em regiões temperadas e até mesmo alguns exemplares em regiões boreais (HUBER, 1994).

Algumas espécies de orquídeas, em estado silvestre, são plantas ameaçadas de extinção, sendo muito importante o desenvolvimento de tecnologias para a propagação e o cultivo em casa de vegetação (MOURA citado por BERNARDI et al., 2004).

As orquídeas, em geral, são plantas epífitas (raízes aéreas), utilizando o hospedeiro (árvores) apenas para fins de fixação. A umidade necessária é proveniente da água da chuva, do orvalho noturno e da umidade relativa do ar (OLIVEIRA, 1993; DEMATTÊ; DEMATTÊ, 1996). Em seus habitat naturais em áreas tropicais ou subtropicais, as orquídeas epífitas crescem em troncos de árvores ou em galhos sob uma carregada cobertura de folhas. As raízes estão expostas e dependem da chuva e da umidade do ar. Por esta razão, as raízes não ficam diretamente em contato com água contendo alto teor de sais. Desta forma, estas plantas podem ser menos tolerantes ao aumento da salinidade do que muitas espécies de plantas terrestres (MILES, 1982).

A técnica de semeadura de orquídeas in vitro torna possível o aproveitamento máximo de sementes, pois quase $100 \%$ das sementes germinam. Porém, esse processo tem como desvantagem a necessidade de um período de aclimatização. A aclimatização é definida como a adaptação climática de um organismo, especialmente uma planta, que é transferida para um novo ambiente, sendo todo esse processo realizado artificialmente. Esta fase é muito delicada, não só porque representa um estresse para a plântula, mas também, pelo perigo de infecções por fungos e bactérias que podem se desenvolver neste estágio (TOMBOLATO; COSTA, 1998). Essa passagem crítica, da fase in vitro para a casa de vegetação, deve-se basicamente aos fatores de estresse hídrico, fotossíntese, absorção de nutrientes e fitossanidade.

Aadubaçãoquímica, commacroemicronutrientes solúveis em água, pode ser feita por aplicação foliar ou radicular, ou ainda, simultânea em folhas e raízes. Contudo, é importante conhecer as diferentes fases do ciclo de desenvolvimento das orquídeas, para que se possa selecionar o adubo a ser empregado e utilizá-lo corretamente (CAMPOS, 2002).

Dos nutrientes essenciais fornecidos por meio de adubação química, destacam-se o nitrogênio, o fósforo e o potássio, que devem ser aplicados em níveis compatíveis às exigências de cada cultura e ao método de adubação utilizado (HAAG et al., 1993).

A adubação via água de irrigação é denominada fertirrigação. Suas vantagens sobre os sistemas convencionais de adubação se traduzem pelo aumento de produtividade, pela redução de mãode-obra, do consumo de energia, dos gastos com equipamentos e pela maior eficiência na utilização de nutrientes pelas plantas (COSTA; FRANÇA; ALVES, 1986).

O objetivo deste trabalho foi avaliar o desenvolvimento vegetativo de plantas de Cattleya intermedia $x$ Laelia purpurata, na fase 
de aclimatização, fertirrigadas com diferentes formulações de N-P-K e com diferentes freqüências de adubação.

O experimento foi realizado no Laboratório de Fitotecnia da Universidade Estadual de Londrina durante o período de janeiro de 2006 a abril de 2007. As plântulas do híbrido intergenérico de Cattleya intermedia Graham ex Hooker x Laelia purpurata Lindley foram obtidas por semeadura in vitro em meio MS (MURASHIGE; SKOOG, 1962), modificado com metade da concentração dos macronutrientes e acrescido de $1 \mathrm{~g} . \mathrm{L}^{-1}$ de carvão ativo, $30 \mathrm{~g} . \mathrm{L}^{-1}$ de sacarose e $7 \mathrm{~g} . \mathrm{L}^{-1}$ de ágar. $\mathrm{O} \mathrm{pH}$ foi ajustado para 5,5, antes da autoclavagem do meio. Posteriormente as culturas foram transferidas para sala de crescimento com 2.000 lux (2.000 $\left.\mu \mathrm{mol} . \mathrm{m}^{-2} \cdot \mathrm{s}^{-1}\right)$ de luminosidade, fotoperíodo de 16 horas-luz e temperatura de aproximadamente $25 \pm 2{ }^{\circ} \mathrm{C}$.

As mudas, após seis meses da semeadura in vitro, com comprimento da parte aérea de 3,0 \pm $0,3 \mathrm{~cm}$, foram retiradas dos frascos e lavadas em água corrente, eliminando-se todo o meio de cultura aderido às raízes. $\mathrm{O}$ cultivo foi realizado em sistema coletivo em bandejas de isopor com $21,5 \mathrm{~cm}$ de comprimento, $14,5 \mathrm{~cm}$ de largura, $3,5 \mathrm{~cm}$ de altura e com oito furos no fundo para proporcionar uma boa drenagem. Foram cultivadas oito mudas por bandeja, e dez bandejas por tratamento. O substrato utilizado foi uma mistura em proporções iguais de casca de arroz carbonizada, fibra de coco e casca de pínus.

Após o plantio, as mudas foram mantidas em casa de vegetação com tela de polipropileno de coloração preta, com retenção de $70 \%$ do fluxo de radiação solar e cobertura plástica. As regas foram realizadas manualmente e diariamente, na quantidade de 50 $\mathrm{mL}$ de água destilada por bandeja.

As formulações líquidas de N-P-K (nitrogênio, fósforo e potássio), aplicadas às plantas, juntamente com a água de irrigação, foram 10:10:10 e 6:6:8 (porcentagens de $\mathrm{N}, \mathrm{P}_{2} \mathrm{O}_{5}$ e $\mathrm{K}_{2} \mathrm{O}$ ), a cada sete e quinze dias, na concentração de 2 g. $\mathrm{L}^{-1}$, durante o período de 10 meses, e mantendo-se um tratamento controle que não recebeu adubação.

Após o período de 10 meses foram avaliados os seguintes parâmetros: comprimento da parte aérea $(\mathrm{cm})$; comprimento da maior raiz $(\mathrm{cm})$; número de pseudobulbos; número de raízes; massa fresca total $(\mathrm{g})$; potencial hidrogeniônico e condutividade elétrica do substrato $\left(\mu \mathrm{S} . \mathrm{cm}^{-1}\right)$.

O delineamento experimental utilizado foi o de blocos inteiramente casualizados, compostos por cinco tratamentos, dez repetições e oito plântulas por parcela. Foi realizada análise de variância e comparação das médias com o teste de Tukey, com intervalo de confiança de $5 \%$.

A maior média para a variável comprimento da parte aérea foi obtida na adubação com N-P-K 10:10:10 em intervalos de quinze dias $(7,41 \mathrm{~cm})$. Os demais tratamentos não diferiram estatisticamente entre si para esse parâmetro (Tabela 1). Poole e Conover (1976) também verificaram em seu trabalho com Aechmea fasciata (Bromeliaceae), que doses crescentes, principalmente de nitrogênio, promoveramocrescimento das plantas, caracterizado pelo aumento de parte aérea. 
Tabela 1. Valores médios de comprimento da parte aérea (CPA), comprimento da maior raiz (CMR), número de pseudobulbos (NP), número de raízes (NR), massa fresca total (MF), pH e condutividade elétrica (CE) de plântulas de Cattleya intermedia x Laelia purpurata fertirrigadas com duas concentrações de N-P-K (06:06:08 e 10:10:10) na dose de 2 g.L. $\mathrm{L}^{-1}$ e dois intervalos de tempo.

\begin{tabular}{|c|c|c|c|c|c|c|c|}
\hline Fertirrigação & CPA (cm) & CMR (cm) & NP & NR & MF (g) & pH & $\mathrm{CE}\left(\mu \mathrm{S} . \mathrm{cm}^{-1}\right)$ \\
\hline Controle & $5,01 b^{1}$ & $11,14 \mathrm{a}$ & $1,86 \mathrm{~b}$ & $3,94 b$ & $3,01 \mathrm{~b}$ & $6,25 \mathrm{ab}$ & $158,60 \mathrm{~b}$ \\
\hline NPK 06:06:08 7dias & $5,86 b$ & $11,00 \mathrm{a}$ & $1,92 b$ & $4,79 \mathrm{ab}$ & $4,33 \mathrm{ab}$ & $6,59 a$ & $168,00 \mathrm{~b}$ \\
\hline NPK 10:10:10 7dias & $5,71 b$ & $10,84 \mathrm{a}$ & $2,41 \mathrm{ab}$ & $5,51 \mathrm{ab}$ & $4,53 \mathrm{ab}$ & $5,46 \mathrm{c}$ & $325,20 \mathrm{a}$ \\
\hline NPK 06:06:08 15dias & $5,64 \mathrm{~b}$ & $11,66 \mathrm{a}$ & $2,31 \mathrm{ab}$ & $4,67 \mathrm{ab}$ & $4,31 \mathrm{ab}$ & $6,76 a$ & $161,60 b$ \\
\hline NPK 10:10:10 15dias & $7,41 \mathrm{a}$ & $11,93 \mathrm{a}$ & $2,66 \mathrm{a}$ & $5,93 \mathrm{a}$ & $5,78 \mathrm{a}$ & $5,77 \mathrm{bc}$ & $210,60 \mathrm{~b}$ \\
\hline C.V. $(\%)$ & 8,40 & 11,54 & 16,10 & 17,97 & 22,86 & 5,71 & 19,50 \\
\hline
\end{tabular}

${ }^{1}$ Médias seguidas pela mesma letra na coluna não diferem entre si pelo teste Tukey a $5 \%$ de probabilidade.

Porém, foi observado que a dosagem de N-P-K 10:10:10 em intervalos menores, como o de sete dias, avaliado no presente trabalho, ocasionaram plantas com comprimento da parte aérea menor em relação as plantas fertirrigadas com a mesma dosagem de N-P-K em intervalos de quinze dias (Tabela 1). Provavelmente isso se deve pela acidificação e pelo aumento do teor de sais solúveis no substrato fertirrigado com N-P-K 10:10:10 a cada sete dias, observados pelos valores de $\mathrm{pH}$ e de condutividade elétrica (Tabela 1).

Segundo Taiz e Zeiger (1991), o pH influencia na disponibilidade de vários nutrientes como nitrogênio, fósforo, potássio, enxofre, cálcio, magnésio, ferro, manganês, boro, cobre, zinco e molibdênio, nos quais a faixa de $\mathrm{pH}$ em que todos estão disponíveis é entre 5,5 a 6,5. Sendo assim, o pH de 5,46 observado nos substratos fertirrigado com N-P-K 10:10:10 a cada sete dias (Tabela 1), encontra-se próximo do limite inferior de disponibilidade dos nutrientes citados por esses autores, podendo ocasionar indisponibilidade de vários nutrientes para a planta, afetando negativamente seu desenvolvimento, caracterizado pelo menor comprimento de parte aérea, como foi observado nas plantas fertirrigadas com N-P-K 10:10:10 a cada sete dias em relação à mesma concentração de N-P-K a cada quinze dias.

O elevado valor de condutividade elétrica observado no substrato que recebeu fertirrigação com N-P-K 10:10:10 a cada sete dias $(325,2 \mu \mathrm{S}$. $\mathrm{cm}^{-1}$ ) pode ter sido outro fator que ocasionou plantas com comprimento da parte aérea menor em relação às que receberam fertirrigação na mesma concentração de N-P-K a cada quinze dias (Tabela 1), pois, segundo Takane, Faria e Altafin (2006), valores elevados de salinidade podem causar perda de água pelas raízes, além de manchas ou queimas nas folhas de orquídeas epífitas, prejudicando o desenvolvimento da planta.

Porém, a salinidade pode não influenciar o desenvolvimento de todas as orquídeas, como foi observado por Wang e Gregg (1994), que realizaram trabalhos variando a condutividade elétrica em Phalaenopsis sp. e não verificaram influência do aumento da salinidade no desempenho dessas orquídeas. No entanto, De Kreij e Van Der Berg (1990), trabalhando com Cymbidium sp., verificaram que o aumento da salinidade do substrato, aumentou o número de cachos de flores por metro quadrado de área de produção, não afetando o número de flores por cacho.

Para o comprimento da maior raiz, não houve diferença significativa entre os tratamentos. Porém, para a variável número de raízes observou-se que a adubação com N-P-K 10:10:10, em intervalos de quinze dias, apresentou melhor resultado em relação às plantas não fertirrigadas, não sendo observada diferença estatística entre esta dose e frequencia de adubação e os demais tratamentos (Tabela 1). 
Em relação ao número de pseudobulbos, observou-se que a adubação com N-P-K 10:10:10 em intervalos de quinze dias apresentou melhor resultado em relação às plantas não fertirrigadas e com fertirrigação com N-P-K 06:06:08 em intervalos de sete dias. Não foi observada diferença estatística entre os demais tratamentos para esse parâmetro (Tabela 1).

Para a variável massa fresca total, as plantas fertirrigadas com N-P-K 10:10:10 em intervalos de quinze dias também apresentaram melhores resultados em relação às plantas controle, porém não diferiu estatisticamente dos demais tratamentos (Tabela 1).

Conclui-se que a fertirrigação com a formulação líquida de N-P-K 10:10:10, a cada quinze dias, na concentração de 2 g. $\mathrm{L}^{-1}$, proporcionou melhor desenvolvimento vegetativo do híbrido intergenérico Cattleya intermedia x Laelia purpurata durante a etapa de aclimatização.

\section{Referências}

BERNARDI, A. C.; FARIA, R. T.; CARVALHO, J. F. R. P.; UNEMOTO, L. K.; ASSIS, A. M. Desenvolvimento vegetativo de plantas de Dendrobium nobile Lindl. fertirrigadas com diferentes concentrações da solução nutritiva de sarruge. Semina: Ciências Agrárias, Londrina, v. 25, n. 1, p. 13-20, 2004.

CAMPOS, D. M. Orquídeas: manual prático de cultura. 3. ed. Rio de Janeiro: Expressão e Cultura, 2002. cap. 5. p. 140-141.

COSTA, E. F.; FRANÇA, G. E.; ALVES, V. M. C. Aplicação de fertilizantes via água de irrigação. Informe Agropecuário, Belo Horizonte, v. 12, n. 139, p .63-69, 1986.

DE KREIJ, C.; VAN DEN BERG, T. J. M. Effect of electrical conductivity of the nutrient solution and fertilization regime on spike production and quality of Cymbidium. Scientia Horticulturae, Amsterdam, v. 44, n. 3/4, p. 293-300, 1990.
DEMATTÊ, J. B.; DEMATTÊ, M. E. S. P. Estudos hídricos com substratos vegetais para o cultivo de orquídeas epífitas. Pesquisa Agropecuária Brasileira, Brasília, v. 31, n. 11, p. 803-808, 1996.

HAAG, H. P.; DECHEN, A. R.; CARMELlO, Q. Q. C.; MONTEIRO, F. A. Princípios de nutrição mineral; aspectos gerais. In: SIMPÓSIO SOBRE NUTRIÇÃO E ADUBAÇÃO DE HORTALIÇAS, 1., 1990, Piracicaba. Anais...Piracicaba: Associação Brasileira para Pesquisa da Potassa e do Fosfato, 1993. p. 51-73.

HUBER, G. Onde se desenvolvem as orquídeas. 5. ed. In: _. (Ed.). Orquídeas. Rio de Janeiro: Expressão e Cultura, 1994. p. 14-16.

MILES, K. Growing equitant Oncidiums. Bulletin of the American Orchidean Society, New York, v. 51, n. 1, p. 155-169, 1982.

MURASHIGE, T.; SKOOG, F. A revised medium for rapid growth and bioassay with tobacco tissue cultures. Physiologia Plantarum, Copenhagen, v. 15, n. 3, p. 473479, 1962.

OLIVEIRA, S. A. A. Noções sobre o cultivo de orquídeas. Boletim CAOB, Rio de Janeiro, v. 5, n. 1, p. 29-35, 1993.

POOLE, R. T.; CONOVER, C. A. Nitrogen, phosphorus, and potassium fertilization of the bromeliad Aechmea fasciata baker. HortScience, Alexandria, v. 11, n. 6, p. 585-586, 1976.

TAIZ, L.; ZEIGER, E. Plant physiology. California: The Benjamim, Cummings Publishing Company, Inc., Redwood City, 1991. 719 p.

TAKANE, R. J.; FARIA, R. T.; ALTAFIN, V. L. Tecnologia fácil - 75: cultivo de orquídeas. Brasília: LK. 2006. $131 \mathrm{p}$.

TOMBolato, A. F. C; COstA, A. M. M. Micropropagação de plantas ornamentais. Campinas: Instituto Agronômico, 1998. (Boletim Técnico, 174).

WANG, Y. T.; GREGG, L. L. Medium and fertilizer affect the performance of Phalaenopsis during two flowering cycles. Horticultural Science, Calcutta, v. 29, n. 1, p. 269-270, 1994. 
